DOI 10.37882/2223-2982.2021.04-2.34

\title{
ВЛИЯНИЕ УРОВНЯ ФИЗИЧЕСКОЙ ПОДГОТОВКИ НА ТРЕНИРОВОЧНЫЙ ПРОЦЕСС БОРЦОВ В РАМКАХ УЧЕБНОЙ ПРОГРАММЫ ВУЗА
}

\section{THE INFLUENCE OF THE PHYSICAL FITNESS LEVEL ON THE PROCESS OF WRESTLERS' TRAINING WITHIN THE UNIVERSITY CURRICULUM FRAMEWORK \\ V. Trunyn \\ T. Akulova \\ O. Nosik \\ N. Plaksina \\ E. Smirnova}

Summary: Fitness, training process and motivation for physical activity are significant and important at all stages of life path. It is no longer a tendency, but a matter of the fact that a decrease in the physical activity of young people leads to significant negative consequences in future, which is far from predictable. These components are of particular importance in the life of the younger generation. The topic is relevant due to the connection between the level of physical fitness of students and the achievement of high sports results in competitive events of student youth. The article presents a comparative analysis of the physical activity criterion and effectiveness attainment. The dependence of the physical level and performance of sportsmen-students is of particular importance in the system of acquiring skills and abilities by students in the structure of the specialization "wrestling". The assessment criteria of the studentathletes preparedness were revealed. On their basis the complex training base of athletes with the use of dynamic and static training was substantiated. The research results are interpreted and presented in tables. The authors formulated generalizing conclusions based on the results of the study.

Keywords: physical education and sport, student-sportsman, physical training, sport specialization, muscle endurance, results growth dynamics, training cycle periods.
Трунин Владимир Владимирович старший преподаватель, ФГБОУ ВО Российский химикотехнологический университет им. Д.И. Менделеева

vtrunin@muctr.ru

Акулова Татьяна Николаевна

дочент, ФГБОУ ВО Российский химико-технологический университет им. Д.И. Менделеева

takulova@muctr.ru

Носик Оксана Владимировна

дочент, ФГБОУ ВО Российский химико-технологический университет им. Д.И. Менделеева

onosik@muctr.ru

Плаксина Надежда Викторовна

старший преподаватель, ФГБОУ ВО Российский химикотехнологический университет им. Д.И. Менделеева

nadegda.compas@rambler.ru

Смирнова Елена Валерьевна

к.т.н., старший преподаватель, ФГБОУ ВО Российский химико-технологический университет им. Д.И. Менделеева evsmirnova@muctr.ru

Аннотация: Физическая подготовка, тренировочный процесс, мотивация к активной физической деятельности на всех этапах жизненного пути являются значимыми и важными. Уже не тенденция, а констатация факта снижения физической активности молодежи приводит к существенным негативным последствиям, причем далеко не прогнозируемого будущего. Особое значение эти составляющие приобретает в жизни молодого поколения. Актуальность темы обусловлена связью уровня физической подготовки обучающихся и достижением высоких спортивных показателей в соревновательных мероприятиях студенческой молодежи. В статье представлен сравнительный анализ критерия физической активности и достижения результативности. Особое значение обусловленность уровня и результативности спортсменов-студентов приобретает в системе приобретения навыков и умений студентами в структуре специализации «борьба». Выявлены оценочные критерии подготовленности студентов-спортсменов, на основании которых обоснована комплексная тренировочная база спортсменов с использованием динамической и статической подготовки. Результаты исследования интерпретированы и представлены в таблицах. По результатам исследования авторами сформулированы обобщающие выводы.

Ключевые слова: физическая культура и спорт, студент-спортсмен, физическая подготовка, спортивная специализация, мышечная выносливость, динамика роста результатов, периоды тренировочного цикла.

\section{Введение}

изическая культура и спорт были и остаются неотъемлемой частью подготовки студентов в рамках формирования компетенций в области культуры двигательной деятельности и всестороннего физического развития специальных качеств, для овладения техническими действиями.

Занятия спортом в образовательной деятельности 
обучающегося высшей школы в опосредованной связи морального воспитания позволяют сформировать гармонично-развитую личность. Федеральным государственным образовательным стандартом высшего образования (ФГОС ВО) определено две дисциплины: «Физическая культура и спорт» и «Физическая культура и спорт (элективные дисциплины)». Учебные занятия по физической культуре и спорту (элективная составляющая) в вузах дают возможность молодым людям выбирать подходящий им вид спорта, совершенствоваться в нем и достигать высоких результатов, тем самым формировать в человеке в целевом результативном компоненте настойчивость и целеустремленность.

Актуальность тематики вопросов влияния спорта на физическое развитие студентов, в дальнейшем, будем рассматривать на примере физической деятельности специализации «борьбы самбо и дзю-до» на кафедре физического воспитания РХТУ им. Д.И. Менделеева.

Физическая подготовка - обязательная составляющая любого вида спорта. С помощью нее достигаются физические качества спортсмена, необходимые для решения основных задач, а именно побед в соревнованиях. В индивидуальных видах спорта, предусматривающих единоборства, роль физической подготовки особенно важна. Борьба, как один из основных видов единоборств, зародилась еще в древности и в наше время по-прежнему очень популярна, при этом многие ее виды являются олимпийскими. В борьбе, как ни в одном другом виде спорта, физическая подготовка - одна из основных составляющих при целом ряде других, таких, как специальная физическая, техническая, моральноволевая, соревновательная, теоретическая. В совокупности всех этих элементов тренировочного процесса решается главная задача - подготовка спортсмена к ответственным соревнованиям. На фоне главной задачи перед физической подготовкой стоит частная задача развивать и совершенствовать необходимые борцу качества, такие как сила, выносливость, быстрота реакции, гибкость, ловкость.

Чтобы оценить степень (уровень) подготовленности студента-спортсмена, должны быть установлены критерии по каждому из этих параметров. Силу борца можно определить по данным динамометрии, а также способностью спортсмена сосредоточить усилия в определенный момент в одном конкретном направлении. Выносливость можно оценить темпом проведения схваток с равными соперниками и временем для полного восстановления сил перед следующей схваткой. Быстрота реакции выявляется в умении быстрее соперника начать атаку (брать захват, «входить» в прием), использовать моменты для атаки, когда соперник менее всего подготовлен, отвечать на прием контрприемом. Гибкость можно оценить подвижностью плечевого и тазобедренного пояса, степенью подвижности суставов рук и ног, крутизной прогиба позвоночника назад («борцовский мост») и вперед. Ловкость может являться результатом выходить из сложных динамических ситуаций, а также находить выгодные решения в данных обстоятельствах движения.

Все перечисленные выше виды подготовки борцов, в том числе и физическая подготовка, должны быть связаны между собой, находясь в постоянном взаимодействии.

В отличие от специализированных школ, спортивных клубов, секций занятия борьбой в вузах профиля проходят в рамках учебной программы кафедры физического воспитания, что влечет за собой специфику подготовки. Студенты посещают тренировки по учебному расписанию в среднем два раза в неделю, что часто является недостаточным для подведения спортсмена к пику лучшей формы (к ответственным соревнованиям) и здесь значительную роль уже играет самоподготовка. Причем, в ней, как наиболее приемлемого элемента, возрастает доля именно физической и специально-физической подготовки.

Но и в рамках учебного процесса физической подготовке уделяется значительное внимание. В завершении каждой тренировки отводится 15 - 20 минут основным физическим упражнениям. Кроме того, 2 - 3 раза в месяц одна из тренировок полностью посвящена функциональной физической подготовке (так называемая круговая силовая подготовка), в которой представлены как обычные упражнения - отжимания из положения, в упоре лежа, упражнения на укрепление мышц брюшного пресса и спины, приседания, прыжки, так и упражнения с использованием спортивных снарядов - канат, перекладина, кольца, гантели, набивные мячи.

При планировании структуры общей физической подготовки борцов используются элементы других видов спорта, таких как: гимнастика, акробатика, тяжелая и легкая атлетика, спортивные игры.

Вопросы общей физической подготовки студентов, структура упражнений, направленных на достижение значимых результатов, отличительные черты и особенности участников спортивной подготовки отражены в исследовании на площадке РХТУ им. Д.И. Менделеева.

\section{Материалы и методы}

Авторское исследование проводилось для достижения следующих целей: установить связь (зависимость) между уровнем физической подготовки обучающихся (общей тренированности) и достижением результативности на соревнованиях. В качестве методологической базы авторы использовали: сравнительный метод, ста- 
тистический анализ, тестирование. Показатели результативности, представленные в табличном варианте, интерпретированы с использованием методики В.Н. Селуянова и методики статической подготовки. В данной работе одной из задач выступала - выявление особенностей физической подготовки студентов-спортсменов, занимающихся в группах спортивного совершенствования специализации борьбы самбо и дзю-до.

Реализация задачи сводилась к следующему. В сравнительном варианте снимались показатели по разным основаниям: целевые групповые аудитории спортсменов-студентов разных курсов, различной степени общей готовности, различных весовых категорий (в сравнительных таблицах указаны данные по некоторым элементам, полученных с применением различных методик, одной из которых является методика стато-динамической физической подготовки профессора В.Н. Селуянова). Предложенная автором методика значительно повышает показатели мышечной выносливости, что является основой подготовки спортсмена-борца.

Методика В.Н. Селуянова направлена на выявление основных взаимосвязей в организме, относящихся к работе мышц и их энергетическому снабжению.

Основываясь на модели мышечного волокна, выносливость мышц зависит от количества митохондрий в них и от содержания, выделяемых ферментов. В этой связи мышечные волокна разделяют на гликолитические и окислительные, и именно последние работают интенсивно, долго и определяют мышечную выносливость. При проведении сравнительного анализа в данной работе использовалась методика проф. В.Н. Селуянова, основанная на структуре тренировки этих видов волокон.

Суть этой тренировки заключается в выполнении упражнений с неполной амплитудой сокращения мышц и при постоянном их напряжении со средней интенсивностью. Продолжительность упражнения составляет 20 - 30 секунд, до боли (жжения) в мышце, интервал отдыха 1 - 3 минуты, количество подходов 1 - 3 тонизирующие, 4 - 8 развивающие.

В дальнейшем, при тестировании спортсменов по спортивным показателям (элементам) в соответствии с данной методикой в таблицы заносятся результаты с указанием максимально возможного времени правильного выполнения упражнения. Показатели, включенные в таблицу в единицы времени «сек», определяют выносливость той или иной группы мышц. Результаты, полученные на основании использования методики, в дальнейшем будем называть результатами статодинамической подготовки (обозначение в таблице - СД).

Другие показатели в таблице по этим же упражнени- ям соответствуют результатам, использования методики статической подготовки. В этом случае спортсмен четко выполняет упражнение максимальное количество раз, без учета времени. К показателям исследования по методике статической подготовки относятся такие, как: отжимание из положения, в упоре лежа, упражнение на брюшной пресс, подтягивание на перекладине (для девушек - на низкой перекладине). В таблицах эти данные обозначены литерой С.

Некоторые виды критериев выполнения (оценивания) упражнений в статике следует прокомментировать: в упражнениях на гибкость критерием являлось расстояние, взятое в сантиметрах, для продольного шпагата - минимальное расстояние от корпуса спортсмена до пола, для гимнастического «мостика» - минимальное расстояние между одноименными опорными руками и ногами.

\section{Результаты и их обсужАение}

Как говорилось ранее, для получения сравнительных показателей были получены результаты тестирования студентов разных курсов, различных гендерных критериев (и юноши, и девушки). Показатели снимались три раза в течение семестра (в начале, середине и в конце, перед итоговыми соревнованиями). Обоснованием для систематического сбора данных явилась необходимость оценки динамики роста (или спада) результатов по основаниям классификаций различных упражнений и, рассмотренным выше методикам.

В общей итоговой таблице 1, каждому студенту присваивался номер от 1 до 11 (№№ 1 - 3 - девушки, №№ 4 - 11 - юноши); они расположены по возрастанию учебного курса, в левой ее части.

1 - показания снимались в начале семестра;

2 - показания снимались в середине семестра;

3 - показания снимались в конце семестра перед официальными соревнованиями.

По результатам, представленным в таблице: наблюдается тенденция роста показателей, причем количественно отличающихся друг от друга, как по конкретным нормативам, так и у каждого из тестируемых. Полученные данные в дальнейшем были использованы для поиска закономерностей и нахождения. Далее был проведен сравнительный анализ.

Примечание: Абсолютные показатели роста или снижения результатов тестирования были бы некорректны и непоказательны для сравнения, поэтому следует ввести простую формулу относительной оценки:

$$
\mathrm{A}=\frac{h 2-h 1}{h 1} 100
$$


где h 2 - данные последнего тестирования;

h 1 - данные первого тестирования;

A - относительный показатель роста в процентах

(для данных по гибкости - h1 и h 2 меняются местами)

Относительный показатель наиболее подходит для сравнения, так как он нивелирует данные спортсменов с учетом индивидуальных особенностей.

На основании данной формулы рассчитан процент роста (или спада) результатов тестирования (показатели представлены в таблице 2).

В таблице также включены данные о количестве тренировок, проведенных спортсменом в течение исследуемого периода (одного семестра).

Сравнивая эти два показателя, можно проследить, в упрощенном виде, зависимость роста результатов физической подготовки, тестируемых от проведенных ими тренировок (рис.1, таблица 2).

Таблица 1.

Показатели тестирования студентов специализации «Самбо» в различные периоды подготовки

\begin{tabular}{|c|c|c|c|c|c|c|c|c|c|c|c|c|c|c|c|c|c|c|c|c|c|}
\hline \multirow{3}{*}{$\begin{array}{c}\text { № студ } \\
\\
1 \\
\end{array}$} & \multicolumn{6}{|c|}{ Отжимание из упора лежа } & \multicolumn{6}{|c|}{ Пресс } & \multicolumn{6}{|c|}{ Гибкость } & \multirow{2}{*}{\multicolumn{3}{|c|}{$\begin{array}{c}\text { Подтягивание } \\
\text { на перекладине } \\
\text { (кол-во раз - } \\
\text { прямой хват) }\end{array}$}} \\
\hline & \multicolumn{3}{|c|}{$\begin{array}{c}\text { С, } \\
\text { кол-во упр. }\end{array}$} & \multicolumn{3}{|c|}{$\begin{array}{c}\text { СД (сек) до } \\
\text { момента потери } \\
\text { верной техники }\end{array}$} & \multicolumn{3}{|c|}{$\begin{array}{c}\text { C, } \\
\text { кол-во упр. }\end{array}$} & \multicolumn{3}{|c|}{$\begin{array}{c}\text { СД (сек) } \\
\text { до момента } \\
\text { потери верной } \\
\text { техники }\end{array}$} & \multicolumn{3}{|c|}{$\begin{array}{c}\text { Продольный } \\
\text { шпагат (см.) рас- } \\
\text { стояние от пола }\end{array}$} & \multicolumn{3}{|c|}{$\begin{array}{c}\text { Гимнастический } \\
\text { мостик (см.) } \\
\text { расстояние между } \\
\text { руками и стопой }\end{array}$} & & & \\
\hline & 1 & 2 & 3 & 1 & 2 & 3 & 1 & 2 & 3 & 1 & 2 & 3 & 1 & 2 & 3 & 1 & 2 & 3 & 1 & 2 & 3 \\
\hline 2 & 16 & 18 & 20 & 34 & 33 & 34 & 37 & 37 & 39 & 74 & 70 & 54 & 3 & 3 & 3 & 29 & 29 & 29 & 6 & 7 & 9 \\
\hline 3 & 10 & 12 & 13 & 25 & 26 & 29 & 31 & 34 & 40 & 43 & 45 & 53 & 9 & 10 & 9 & 60 & 59 & 56 & 4 & 4 & 6 \\
\hline 4 & 20 & 21 & 25 & 40 & 41 & 49 & 36 & 38 & 43 & 45 & 52 & 60 & 8 & 6 & 3 & 14 & 10 & 0 & 12 & 13 & 15 \\
\hline 5 & 58 & 65 & 75 & 39 & 42 & 48 & 58 & 70 & 85 & 01 & 84 & 92 & 30 & 28 & 23 & 61 & 54 & 48 & 12 & 11 & 13 \\
\hline 6 & 60 & 61 & 65 & 63 & 64 & 66 & 50 & 50 & 52 & 43 & 50 & 60 & 29 & 26 & 20 & 79 & 71 & 59 & 14 & 17 & 21 \\
\hline 7 & 42 & 46 & 52 & 45 & 47 & 50 & 63 & 65 & 70 & 43 & 50 & 60 & 36 & 30 & 29 & 49 & 45 & 37 & 9 & 10 & 13 \\
\hline 8 & 50 & 53 & 55 & 31 & 33 & 35 & 40 & 40 & 43 & 38 & 40 & 40 & 27 & 20 & 19 & 47 & 45 & 43 & 3 & 3 & 3 \\
\hline 9 & 50 & 57 & 60 & 45 & 48 & 54 & 50 & 50 & 51 & 70 & 41 & 45 & 32 & 30 & 26 & 49 & 45 & 39 & 12 & 12 & 13 \\
\hline 10 & 20 & 24 & 31 & 43 & 45 & 48 & 63 & 65 & 70 & 33 & 35 & 39 & 24 & 20 & 15 & 50 & 45 & 39 & 5 & 5 & 6 \\
\hline 11 & 42 & 52 & 60 & 48 & 50 & 55 & 70 & 71 & 76 & 71 & 75 & 80 & 29 & 23 & 20 & 76 & 72 & 66 & 7 & 8 & 10 \\
\hline
\end{tabular}

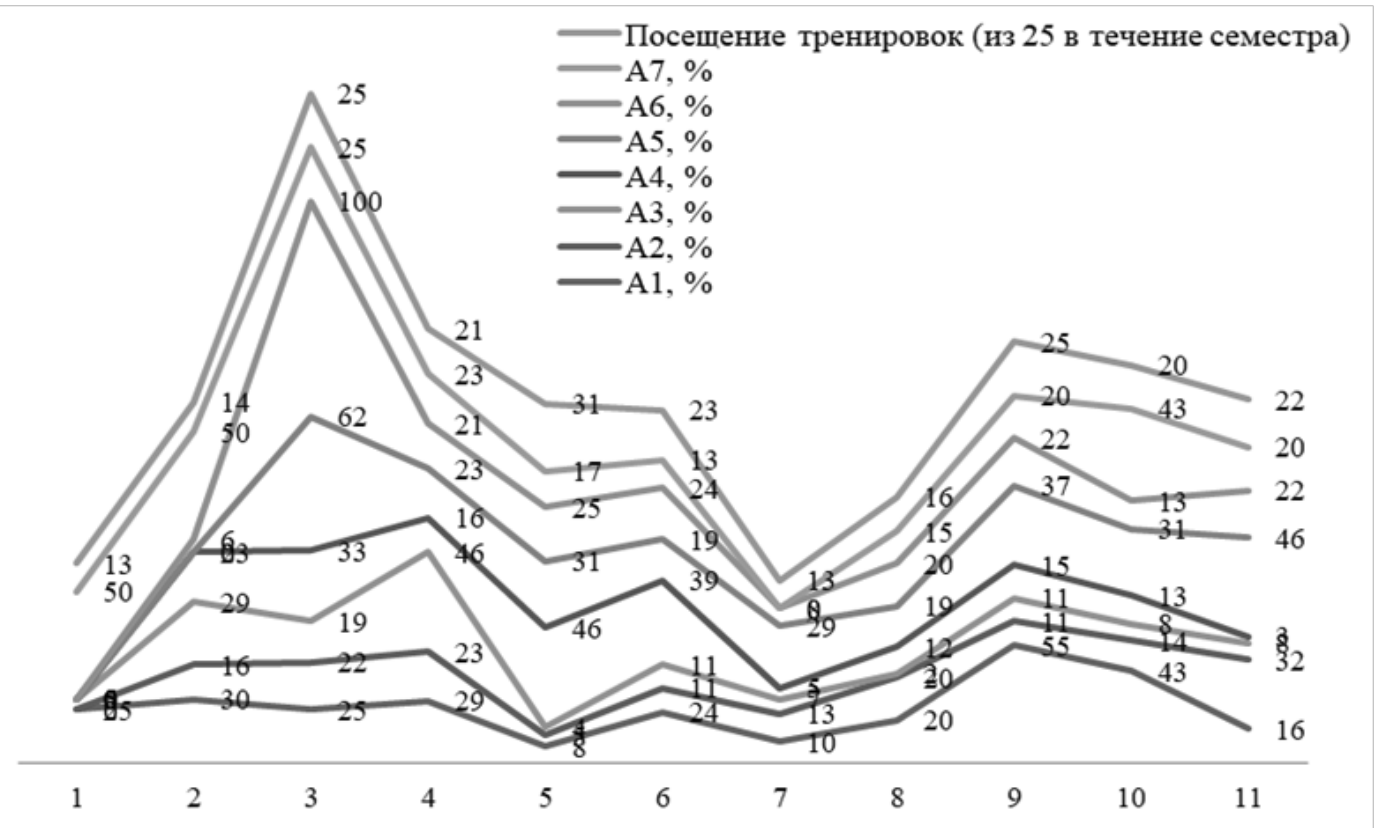

Рис.1. Зависимость результатов физической подготовки от количества тренировоктренировки 
И наконец, для ответа на основной вопрос исследования о влиянии роста физической формы на специальную подготовленность спортсмена, обобщим полученные данные и сравним их с результатами испытуемых, достигнутыми на ответственных соревнованиях (рис.2, таблица 3).

В представленной таблице, для наглядности, введем понятие общего показателя роста физической подготовленности спортсмена, а именно, суммируем процент роста данных по разным упражнениям и разделим их на количество последних, получаем формулу:

$$
\text { Аобщ }=\frac{(A 1+A 2+A 3+\cdots+A 7)}{7}
$$

В следующих графах в таблице 3 указаны места, занятые спортсменом на предыдущем ближайшем соревновании и на соревновании в конце исследуемого периода.

Анализируя полученные результаты, можно заметить, что в подавляющем числе случаев, рост соревновательной готовности наблюдается у спортсменов с наи-

Относительные показатели роста (спада) результатов тестирования

\begin{tabular}{|c|c|c|c|c|c|c|c|c|}
\hline \multirow{2}{*}{$\begin{array}{l}\text { Номер } \\
\text { студента }\end{array}$} & \multicolumn{2}{|c|}{$\begin{array}{c}\text { Отжимание, из упора лежа, } \\
\text { кол-во раз }\end{array}$} & \multicolumn{2}{|c|}{ Пресс, кол-во раз } & \multicolumn{2}{|c|}{ Гибкость, см } & \multirow{2}{*}{$\begin{array}{c}\text { Подтягивание } \\
\text { на переклади- } \\
\text { не, кол-во раз } \\
\text { A7 \% }\end{array}$} & \multirow{2}{*}{$\begin{array}{c}\text { Посещения } \\
\text { тренировок } \\
\text { (из всех 25-ти } \\
\text { возможных, } \\
\text { в течение } \\
\text { семестра) }\end{array}$} \\
\hline & $\mathrm{A} 1 \%$ & A2 $\%$ & A3 $\%$ & A4 \% & A5 \% & A6\% & & \\
\hline 1 & 25 & 0 & 5 & 0 & 0 & 0 & 50 & 13 \\
\hline 2 & 30 & 16 & 29 & 23 & 0 & 6 & 50 & 14 \\
\hline 3 & 25 & 22 & 19 & 33 & 62 & 100 & 25 & 25 \\
\hline 4 & 29 & 23 & 46 & 16 & 23 & 21 & 23 & 21 \\
\hline 5 & 8 & 5 & 4 & 46 & 31 & 25 & 17 & 31 \\
\hline 6 & 24 & 11 & 11 & 39 & 19 & 24 & 13 & 23 \\
\hline 7 & 10 & 13 & 7 & 5 & 29 & 8 & 0 & 13 \\
\hline 8 & 20 & 20 & 2 & 12 & 19 & 20 & 15 & 16 \\
\hline 9 & 55 & 11 & 11 & 15 & 37 & 22 & 20 & 25 \\
\hline 10 & 43 & 14 & 8 & 13 & 31 & 13 & 43 & 20 \\
\hline 11 & 16 & 32 & 8 & 3 & 46 & 22 & 20 & 22 \\
\hline
\end{tabular}

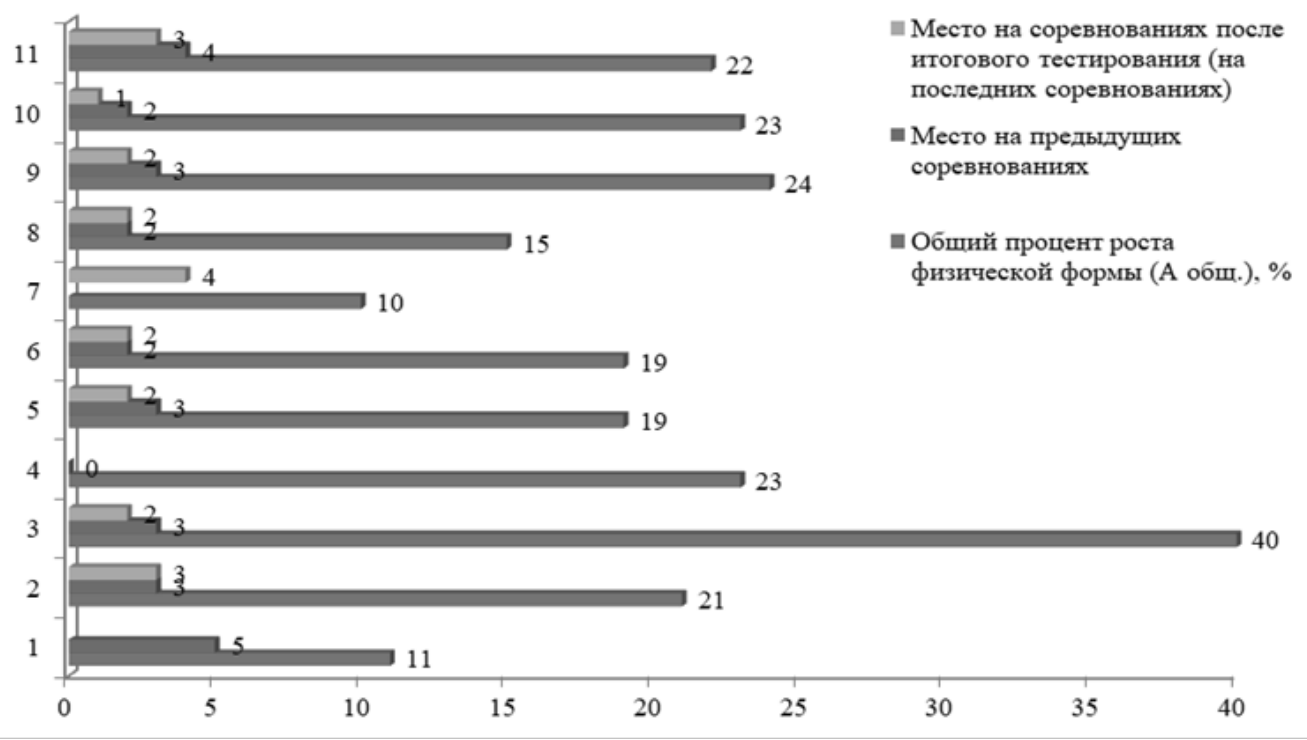

Рис. 2. Зависимость соревновательной готовности спортсмена от динамики роста их физической подготовленности 
Показатели зависимости соревновательной готовности спортсменов от динамики роста их физической подготовленности

\begin{tabular}{|c|c|c|c|}
\hline Номер студента & $\begin{array}{c}\text { Общий процент роста физической } \\
\text { формы (А общ.), }\end{array}$ & $\begin{array}{c}\text { Место на предыдущих } \\
\text { соревнованиях } \\
\text { иесто на соревнованиях после } \\
\text { итового тестирования } \\
\text { (на последних соревнованиях) }\end{array}$ \\
\hline 2 & 11 & 5 & 3 \\
\hline 3 & 21 & 3 & 2 \\
\hline 4 & 40 & Не участвовала участвовал & Не участвовал \\
\hline 5 & 23 & 3 & 2 \\
\hline 6 & 19 & 2 & 2 \\
\hline 7 & 19 & Не участвовал & 4 \\
\hline 8 & 10 & 2 & 2 \\
\hline 9 & 15 & 3 & 2 \\
\hline 10 & 24 & 2 & 1 \\
\hline
\end{tabular}

лучшей степенью физической подготовки.

В любом исследовании все полученные результаты не подчиняются строгой зависимости, всегда есть исключения и некоторые искажения валидности, и только после набора достаточного количества статистических данных можно проследить определенную связь между параметрами.

\section{Выво $\Delta ы$}

На основании проведенного анализа можно сделать ряд выводов.

Рост показателей физической подготовки зависит от продолжительности (времени), проведенного на тренировках.

Не для всех категорий спортсменов зависимость роста показателей одинакова, необходимо учитывать индивидуальные особенности каждого (общее физическое состояние, антропометрические данные).

Как и следовало ожидать, прослеживается тенденция роста общей тренированности от положительных результатов физической готовности. Представленная работа не претендует на роль глубокого научного исследования, авторы лишь попытались в некотором роде обозначить и оценить влияние общей физической подготовки студентов в рамках учебного процесса. Эти рамки (границы) в должной мере ограничивают глубину исследований по заявленной тематике, но дают определенные шансы на тенденцию совершенствования учебного процесса, направленного на эффективность использования методик и универсальных комплексов упражнений, направленных на реальную возможность и перспективу достижения рекордов студенческой молодежью. Уровень престижности вуза и ранг в списке лучших образовательных учреждений высшей школы определяется и показателем вклада студентов-спортсменов в рейтинг спортивных достижений, рекордов и достойных победных пьедесталов.

В заключение отметим, что, даже абстрагируясь от основной темы работы о влиянии физической подготовки на спортивные результаты, не только в борьбе, но и в любом другом виде спорта, можно сделать вывод, что хорошая физическая форма придает уверенность, мобилизует и мотивирует человека к успешной творческой деятельности.

\section{ЛИТЕРАТУРА}

1. Чумаков Е.М. Сто уроков самбо / Е.М. Чумаков. - Москва: ФАИР-ПРЕСС, 1998 - 400 с.

2. Турин Л.Б. Борьба самбо / Л.Б. Турин. - Москва: Советская Россия, 1963 - 203 с.

3. Селуянов В.Н. Принципы построения силовой тренировки / В.Н. Селуянов // Юбилейный сборник трудов ученых РГАФК, посвященный 80-летию академии - Москва: РГАФК - 1998 - Т 2. - С. 39-49.

4. Силина В.И. Дзюдо / В.И. Силина. Сокр. пер. с япон. - Москва: Физкультура и спорт, 1977 - 104 с. 
5. Портал Федеральных государственных образовательных стандартов высшего образования: [Электронный ресурc]. - MockBa, 2021. - URL: http://fgosvo. ru/fgosvo/92/91/4 (дата обращения: 05.03.2021). - Текст: электронный.

6. Спортивная борьба. Ежегодник / Сост. О.П. Юшков, В.П. Сердюк. - Москва: ФиС, 1983.

7. Акулова Т.Н. Подготовка самбистов-разрядников в летний период / Т.Н. Акулова, В.В. Трунин, В.А. Головина // Вестник РХТУ им. Д.И. Менделеева. Гуманитарные и социально-экономические исследования, Том № 1 Гуманитарные исследования, Выпуск № VII. - Москва: РХТУ им. Д.И. Менделеева, 2016. - C. 95-101.

8. Учебник Дзюдо / Р.А. Лайшев, К.Г. Тиновицкий, И.В. Емельянова. - Москва: 000 «Информполиграф», 2015. - 300 с.

9. Физическая культура. Самбо: Учебно-методический комплекс / сост. Т.Н. Акулова, В.А. Головина, В.Д. Щербинина. - Москва: РХТУ им. Д.И. Менделеева, 2013. $-80 \mathrm{c}$.

( ) Трунин Владимир Владимирович (vtrunin@muctr.ru), Акулова Татьяна Николаевна (takulova@muctr.ru),

Носик Оксана Владимировна (onosik@muctr.ru), Плаксина Надежда Викторовна (nadegda.compas@rambler.ru),

Смирнова Елена Валерьевна (evsmirnova@muctr.ru).

Журнал «Современная наука: актуальные проблемы теории и практики»

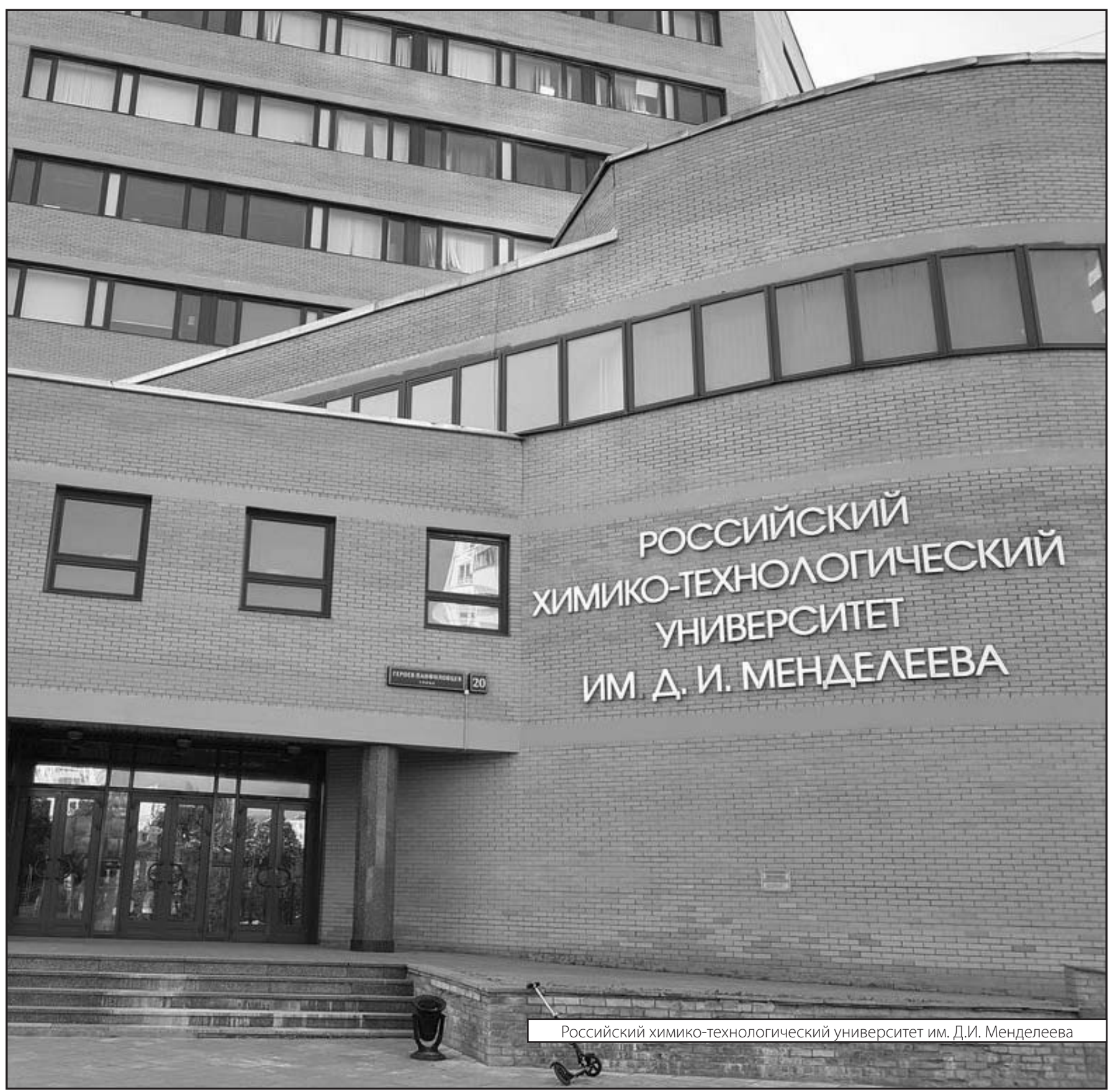

